PAPER

\title{
Stimulation of the subthalamic nucleus in Parkinson's disease: a 5 year follow up
}

\begin{abstract}
W M M Schüpbach, N Chastan, M L Welter, J L Houeto, V Mesnage, A M Bonnet, V Czernecki, D Maltête, A Hartmann, L Mallet, B Pidoux, D Dormont, S Navarro, P Cornu, A Mallet, Y Agid
\end{abstract}

J Neurol Neurosurg Psychiatry 2005;76:1640-1644. doi: 10.1136/jnnp.2005.063206

See end of article for authors' affiliations

Correspondence to: Dr Y Agid, Centre d'Investigation Clinique, Hôpital de la Salpêtrière 47 boulevard de l'Hôpital, 75013 Paris, France; yves. agid@psl.ap-hop-paris.fr

Received 12 January 2005 Revised version received 23 March 2005

Accepted 11 April 2005

\begin{abstract}
Background: The short term benefits of bilateral stimulation of the subthalamic nucleus (STN) in patients with advanced levodopa responsive Parkinson's disease (PD) are well documented, but long term benefits are still uncertain.

Objectives: This study provides a 5 year follow up of PD patients treated with stimulation of the STN.

Methods: Thirty seven consecutive patients with PD treated with bilateral STN stimulation were assessed prospectively 6, 24, and 60 months after neurosurgery. Parkinsonian motor disability was evaluated with and without levodopa treatment, with and without bilateral STN stimulation. Neuropsychological and mood assessments included the Mattis Dementia Rating Scale, the frontal score, and the MontgomeryAsberg Depression Rating Scale (MADRS).

Results: No severe peri- or immediate postoperative side effects were observed. Six patients died and one was lost to follow up. Five years after neurosurgery: (i) activity of daily living (Unified Parkinson Disease Rating Scale (UPDRS) II) was improved by stimulation of the STN by 40\% ("off" drug) and 60\% ("on" drug); (ii) parkinsonian motor disability (UPDRS III) was improved by 54\% ("off" drug) and 73\% ("on" drug); (iii) the severity of levodopa related motor complications was decreased by $67 \%$ and the levodopa daily doses were reduced by $58 \%$. The MADRS was unchanged, but cognitive performance declined significantly. Persisting adverse effects included eyelid opening apraxia, weight gain, addiction to levodopa treatment, hypomania and disinhibition, depression, dysarthria, dyskinesias, and apathy.

Conclusions: Despite moderate motor and cognitive decline, probably due to disease progression, the marked improvement in motor function observed postoperatively was sustained 5 years after neurosurgery.
\end{abstract}

A lthough levodopa treatment remains the gold standard for the treatment of Parkinson's disease (PD), long term results are hampered by motor complications such as dyskinesias and fluctuations. ${ }^{1}$ In severe levodopa responsive forms of the disease with motor complications, continuous bilateral high frequency stimulation of the subthalamic nucleus (STN) is a promising therapeutic option. ${ }^{2}$ However, the short term outcome of this treatment is still uncertain. According to some studies, STN stimulation offers an unique opportunity both to improve parkinsonian motor disability and levodopa related motor complications, and to reduce the daily dose of levodopa by more than $60 \% .^{3-5}$ Other groups, however, have obtained less satisfactory results. ${ }^{6-8}$ Little is known about the long term outcome of STN stimulation. There is only one report of a 5 year follow up of a cohort of 49 patients with advanced PD who underwent surgery. ${ }^{9}$ We present here the results obtained in a series of 37 consecutive PD patients who were assessed in our centre $6(n=37), 24(n=32)$, and 60 months $(n=30)$ after bilateral stimulation of the STN.

\section{METHODS}

\section{Patients}

Between February 1996 and July 1999, 37 patients (24 men and 13 women) with severe levodopa responsive PD were treated with bilateral stimulation of the STN. Two of the patients had previously been treated with bilateral internal pallidal stimulation which was abandoned in favour of STN stimulation because of the recurrence of parkinsonian symptoms after 2 years. The selection criteria for neurosurgery were: (i) advanced clinically diagnosed $\mathrm{PD}^{10}$ (median (interquartile range, IQR) Hoehn and Yahr score ${ }^{11} 5$ (4-5) "off" medication; mean (standard deviation, SD) Schwab and England score ${ }^{12} 38.3 \%$ (21.8\%) "off" medication; mean (SD) disease duration at time of surgery 15.2 (5.3) years); (ii) $\geqslant 40 \%$ improvement in motor symptoms in response to levodopa treatment (median improvement 69\%, IQR 55$77 \%$ ); (iii) occurrence of severe levodopa related motor complications despite optimal adjustment of antiparkinsonian medication (mean (SD) daily dose of levodopa equivalent $^{13} 1468$ (811) mg); (iv) less than 70 years of age at the time of surgery (mean (SD) age 54.9 (9.1) years) except for two patients aged 71 and 74; (v) absence of dementia (mean (SD) Mattis Dementia Rating Scale ${ }^{14}$ score 140.2 (3.9); mean (SD) "frontal" score ${ }^{15} 43.2$ (7.2)) or major ongoing psychiatric disorders including depression $\left(\right.$ MADRS $^{16}$ score (SD) 10.9 (5.6)); and (vi) absence of neurosurgical and neuroradiological contra-indications. ${ }^{17}$ All patients gave informed written consent according to the Declaration of Helsinki, ${ }^{18}$ and the study was approved by the local Ethical Committee of the Groupe Hospitalier Pitié-Salpêtrière, Paris, France.

\section{Neurosurgical procedure}

The neurosurgical procedure was performed as previously described.${ }^{17}$ The electrodes were implanted in one operation under local anaesthesia using an approach combining intra-operative recording and stimulation. ${ }^{19}$ The definitive

Abbreviations: $A D L$, activities of daily living; $I Q R$, interquartile range; MADRS, Montgomery-Asberg Depression Rating Scale; PD, Parkinson's disease; SD, standard deviations; STN, subthalamic nucleus; UPDRS, Unified Parkinson Disease Rating Scale 
quadripolar electrodes (model 3389-28; Medtronic, Minneapolis, MN, USA) were implanted bilaterally and connected to a subcutaneous programmable pulse generator (Itrel II; Medtronic) in the subclavicular area. Electrical parameters (voltage, pulse width, and frequency) were progressively adjusted using an electromagnetic programmer (7532 neurological programmer; Medtronic).

\section{Clinical evaluation}

Patients were systematically examined 1 month before surgery and 6, 24, and 60 months after surgery. Activities of daily living (ADL; Unified Parkinson Disease Rating Scale ${ }^{20}$ (UPDRS) part II) were scored during an interview evaluating the "off" and "on" drug conditions. After surgery, the percentage improvement in ADL was calculated with respect to the preoperative ADL "off" medication score. Before surgery, evaluation of motor disability (UPDRS part III) was performed in the "off" state as defined by the Core Assessment Program for Intracerebral Transplantation (CAPIT) in $\mathrm{PD}^{21}$ that is at least $12 \mathrm{~h}$ after withdrawal of antiparkinsonian medication, and in the best "on" drug condition after the administration of a single suprathreshold dose of levodopa (50 mg more than the usual effective dose taken in the morning). The "axial" score was defined as the sum of the following motor subscores: speech, rising from a chair, posture, postural stability and gait (items 18, 27, 28, 29, and 30 of the UPDRS part III). The axial score was assessed in the same "off" and "on" drug conditions. After surgery, the parkinsonian motor disability and axial scores were evaluated in four conditions: (i) "off" stimulation and "off" drug, after a night without drug treatment and after stimulation had been switched off for $12 \mathrm{~h}$ (first 27 patients) or for at least $1.5 \mathrm{~h}$ ( 10 patients); (ii) "on" stimulation and "off" drug, after stimulation had been switched on for at least I h; (iii) "off" stimulation and "on" drug, after stimulation had been switched off for at least $1 \mathrm{~h}$ and after the administration of a suprathreshold dose of levodopa (equivalent to the preoperative dose), and (iv) "on" stimulation and "on" drug, after stimulation had been switched on using the chronic stimulation parameters. All four conditions were evaluated on the same day. The percentage improvement in overall motor disability and axial scores was calculated with respect to the preoperative "off" drug condition. Levodopa related complications were evaluated using the UPDRS part IV including the scores for motor fluctuations (part IV-A) and levodopa induced dyskinesias (part IV-B). The severity of the disease was assessed using the Hoehn and Yahr and the Schwab and England scores in the "off" and "on" drug conditions. Neuropsychological and mood assessments included the Mattis, frontal, and MADRS scores under long term STN stimulation and antiparkinsonian treatment.

\section{Statistical analysis}

Primary outcome measures were grouped into four categories: (i) motor assessment (UPDRS part III, including the axial score); (ii) ADL (UPDRS part II); (iii) treatment and treatment related complications (UPDRS part IV, including the subscores UPDRS IV-A for motor fluctuations and UPDRS IV-B for dyskinesias; daily levodopa equivalent dose; stimulation strength); (iv) neuropsychological assessment (Mattis, frontal, and MADR scales; UPDRS I). A Bonferroni correction was performed to control for the familywise type I error rate within each of these categories, and the results were considered to be significant for the outcome measures of categories (i) to (iv) at p<0.017, 0.05, 0.01, and 0.013, respectively. The effects of continuous bilateral STN stimulation on parkinsonian symptoms were analysed using repeated measures analysis of variance. Dependent variables were the raw primary outcome measures. Independent variables were the sequence of assessment (that is, time) for all outcome measures, and medication status ("on" or "off" medication), stimulation status ("on" or "off" stimulation), and the interaction between these variables, where appropriate. Differences between single assessments were analysed only if a significant global effect was present and no correction for these pairwise comparisons was made. Comparison of the long term benefits of stimulation and drug treatment on axial and non-axial motor signs, expressed relative to the pre-operative "off" state, was performed with the Wilcoxon signed rank test. Only patients surviving at least 5 years after surgery were included in the statistical analyses. The data are presented as means (SD) except for percentages of improvement for which the medians are given. Statistical analysis was performed with the SAS statistical software package (SAS Institute, Cary, NC, USA).

\section{RESULTS}

During the 60 month follow up period, six patients died: two died as a result of worsened motor disability, mainly axial, attributed to progression of the disease; one committed suicide; one died from spontaneous cerebral bleeding of unknown cause 4 years after neurosurgery; and two died suddenly of an unidentified cause (one of whom was found to have multiple system atrophy at autopsy). One patient moved away and was lost to follow up. Thirty seven patients were evaluated before and 6 months after surgery, 32 patients at 24 months, and 30 patients at 60 months after surgery.

\section{Effects of continuous bilateral stimulation of the subthalamic nucleus on parkinsonian motor disability} Before surgery, there was a $69 \%$ improvement in parkinsonian motor disability (UPDRS III) at the time of maximal clinical improvement following the administration of a single suprathreshold dose of levodopa (table 1). Six, 24, and 60 months after surgery, the motor disability score was improved by 59, 69, and 54\%, respectively, with STN stimulation alone ("on" stimulation "off" drug), and by 60 , 75 , and 59\% under levodopa treatment alone ("off" stimulation "on" drug). The combination of STN stimulation with levodopa administration produced significantly greater motor improvement $(81,85$, and $73 \%$ at 6,24 , and 60 months after surgery) than obtained postoperatively with either levodopa ("off" stimulation "on" drug) or stimulation ("on" stimulation "off" drug) alone. This effect, also observed for the parkinsonian axial score, was sustained during the entire follow up, although both the UPDRS III and axial scores worsened significantly over the postoperative period. The long term benefit 60 months after neurosurgery was higher for non-axial signs (median 76\%, "on" stimulation "on" drug) than for axial signs (53\%) of the UPDRS III, with a median difference of $16 \%$ ( $\mathrm{p}<0.0003$, not shown).

Levodopa related motor complications (UPDRS IV) were improved by 88,83 , and $67 \%$ at 6,24 , and 60 months after neurosurgery, respectively (table 1). The UPDRS IV score at the end of the study was significantly worse than at 6 months after surgery. The severity of motor fluctuations and levodopa induced dyskinesias was diminished by 100 , 100 , and $67 \%$, and 86,86 , and $79 \%$, respectively, at 6,24 , and 60 months after surgery. The UPDRS IV subscores for dyskinesias and motor fluctuations remained significantly better than the preoperative state throughout the follow up period, but showed a tendency to worsen with time that did not reach statistical significance.

Six, 24, and 60 months after surgery, the daily dose of levodopa equivalent was decreased by 64,63 , and $58 \%$ (table 1). Six months after surgery, STN stimulation was 
Table 1 Activities of daily living, parkinsonian motor disability, and levodopa related complications before and 6, 24, and 60 months after neurosurgery

\begin{tabular}{|c|c|c|c|c|c|c|c|}
\hline & \multirow[b]{3}{*}{$\begin{array}{l}\text { Before } \\
\text { surgery }\end{array}$} & \multicolumn{6}{|l|}{ After surgery } \\
\hline & & \multicolumn{2}{|l|}{6 months } & \multicolumn{2}{|l|}{24 months } & \multicolumn{2}{|l|}{60 months } \\
\hline & & $\begin{array}{l}\text { "Off" } \\
\text { stimulation }\end{array}$ & $\begin{array}{l}\text { "On" } \\
\text { stimulation }\end{array}$ & $\begin{array}{l}\text { "Off" } \\
\text { stimulation }\end{array}$ & $\begin{array}{l}\text { "On" } \\
\text { stimulation }\end{array}$ & $\begin{array}{l}\text { "Off" } \\
\text { stimulation }\end{array}$ & $\begin{array}{l}\text { "On" } \\
\text { stimulation }\end{array}$ \\
\hline \multicolumn{8}{|l|}{ ADL (UPDRS II) } \\
\hline "Off" drug & $30.4(8.7) \dagger$ & & $\begin{array}{l}11.8(7.2)^{*} \text {, } \\
67 \%\end{array}$ & & $\begin{array}{l}13.1(9.0)^{*} \S \\
68 \%\end{array}$ & & $\begin{array}{l}19.2(9.9)^{*}+\S \oplus, \\
40 \%\end{array}$ \\
\hline "On" drug & $\begin{array}{l}11.5(8.2)^{*} \\
67 \%\end{array}$ & & $\begin{array}{l}6.6(4.7)^{*} \dagger \pm \\
81 \%\end{array}$ & & $\begin{array}{l}10.0(8.7)^{\star} \mp \S \\
72 \%\end{array}$ & & $\begin{array}{l}14.3(9.1)^{*} \neq \S \Subset, \\
60 \%\end{array}$ \\
\hline \multicolumn{8}{|l|}{$\begin{array}{l}\text { Parkinsonian motor } \\
\text { disability (UPDRS III) }\end{array}$} \\
\hline "Off" drug & $51.9(17.2) \dagger$ & 46.7 (19.2) & $\begin{array}{l}19.9(15.2)^{*} \\
59 \%\end{array}$ & $42.5(15.6)$ & $\begin{array}{l}18.0(12.3)^{*} \\
69 \%\end{array}$ & $51.3(15.4)$ & $\begin{array}{l}26.2(13.6)^{*}+\uparrow, \\
54 \%\end{array}$ \\
\hline "On" drug & $\begin{array}{l}17.8(10.6)^{*} \\
69 \%\end{array}$ & $\begin{array}{l}20.4(13.3)^{*} \\
60 \%\end{array}$ & $\begin{array}{l}11.3(9.7)^{*} \dagger \neq \\
81 \%\end{array}$ & $\begin{array}{l}16.2(13.2)^{*} \\
75 \%\end{array}$ & $\begin{array}{l}10.1(9.9)^{*} \dagger \neq \\
85 \%\end{array}$ & $\begin{array}{l}24.1(14.2)^{\star} \mp, \\
59 \%\end{array}$ & $\begin{array}{l}17.9(12.3)^{*} \mp \oplus, \\
73 \%\end{array}$ \\
\hline \multicolumn{8}{|l|}{ Axial score } \\
\hline "Off" drug & $11.6(3.8) \dagger$ & $9.5(4.5)$ & $\begin{array}{l}4.8(4.0)^{*}, \\
71 \%\end{array}$ & $9.2(4.3)$ & $\begin{array}{l}5.0(3.8)^{*}, \\
61 \%\end{array}$ & $11.4(4.2)$ & $\begin{array}{l}7.0(3.8)^{*} \dagger \S \uparrow, \\
43 \%\end{array}$ \\
\hline "On" drug & $\begin{array}{l}4.8(3.1)^{*} \\
62 \%\end{array}$ & $\begin{array}{l}4.3(3.5)^{*} \\
71 \%\end{array}$ & $\begin{array}{l}2.6(2.6)^{*} \dagger \ddagger \\
85 \%\end{array}$ & $\begin{array}{l}4.6(3.8)^{*} \\
67 \%\end{array}$ & $\begin{array}{l}3.8(3.3)^{*} \dagger \mp, \\
71 \%\end{array}$ & $\begin{array}{l}6.3(4.2)^{*} \S \uparrow, \\
53 \%\end{array}$ & $\begin{array}{l}5.8(3.7)^{\star} \pm \S \uparrow, \\
53 \%\end{array}$ \\
\hline \multicolumn{8}{|l|}{$\begin{array}{l}\text { Levodopa related } \\
\text { complications }\end{array}$} \\
\hline UPDRS IV & $12.7(2.6)$ & & $2.5(2.5) \dagger, 88 \%$ & & $3.2(3.2) \dagger, 83 \%$ & & $5.1(4.1) \dagger \S, 67 \%$ \\
\hline Motor fluctuations & $4.7(1.2)$ & & $0.8(1.2) \dagger, 100 \%$ & & $0.8(1.4) \dagger, 100 \%$ & & $1.4(1.4) \dagger, 67 \%$ \\
\hline Dyskinesias & $6.9(2.5)$ & & $1.4(1.7)+, 86 \%$ & & $2.0(2.2) \dagger, 86 \%$ & & $2.8(2.9) \dagger, 79 \%$ \\
\hline $\begin{array}{l}\text { Levodopa equivalent } \\
\text { doses (mg/day) }\end{array}$ & $1468(811)$ & & $559(433) \dagger, 64 \%$ & & $652(448) \dagger, 63 \%$ & & $667(504) \dagger, 58 \%$ \\
\hline \multicolumn{8}{|c|}{$\begin{array}{l}\text { Values are means (SD), median percentage improvement. The median percentage improvement is in comparison to the preoperative "off" drug condition, for } \\
\text { UPDRS IV in comparison to the preoperative "on" drug condition. } \\
\text { "p significant compared with the "off" drug condition before surgery (see Methods). } \\
\text { tp significant compared with the "on" drug condition before surgery (see Methods). } \\
\text { tp significant compared with the "on" stimulation "off" drug condition (see Methods). } \\
\text { \$p significant compared with the corresponding assessment } 6 \text { months after surgery (see Methods). } \\
\text { Tp significant compared with the corresponding assessment } 24 \text { months after surgery (see Methods). }\end{array}$} \\
\hline
\end{tabular}

monopolar cathodic on 64 leads (29 patients) and double monopolar on 10 leads (eight patients). The mean (SD) voltage, pulse width, and frequency of stimulation were 2.6 (0.4) V, 61 (5) $\mu \mathrm{s}$, and $148(28) \mathrm{Hz}$ for the right stimulation contact, and 2.7 (0.3) V, 65 (14) $\mu \mathrm{s}$, and 157 (30) Hz for the left stimulation contact. Twenty four months after surgery, stimulation was monopolar cathodic on 63 leads, parallel double monopolar on five leads, parallel triple monopolar on one lead, and bipolar on one lead. The mean (SD) intensity, pulse width, and frequency of stimulation were $2.7(0.4) \mathrm{V}$, 63 (9) $\mu$ s, and $151(26) \mathrm{Hz}$ for the right, and 2.9 (0.4) V, 63 (10) $\mu \mathrm{s}$, and $153(27) \mathrm{Hz}$ for the left stimulation contacts. Sixty months after surgery, stimulation was monopolar cathodic on 49 leads, parallel double monopolar on eight leads, parallel triple monopolar on one lead, and bipolar on one lead. The mean (SD) intensity, pulse width, and frequency of stimulation were $2.8(0.4) \mathrm{V}, 64$ (10) $\mu \mathrm{s}$, and 150 (27) $\mathrm{Hz}$ for the right, and $2.9(0.4) \mathrm{V}, 62$ (8) $\mu$ s, and 148 (26) $\mathrm{Hz}$ for the left stimulation contact.

\section{Effects of continuous bilateral stimulation of the subthalamic nucleus on activities of daily living and neuropsychological status}

Before surgery, antiparkinsonian drug treatment improved the ADL score (UPDRS II) by 67\%. Six, 24, and 60 months after surgery, the ADL score was improved by 67,68 , and $40 \%$ when patients were under continuous STN stimulation without drug treatment ("on" stimulation "off" drug) and 81,72 , and $60 \%$ with STN stimulation and drug treatment ("on" stimulation "on" drug) (table 1). Although the ADL score under STN stimulation and drug treatment ("on" stimulation "on" drug) 6 months after surgery was better than the preoperative score in the "on condition", this was no longer true 24 and 60 months after surgery. The UPDRS part I, Mattis, and frontal scores remained unchanged 6 and 24 months after the operation compared to the pre-operative state, but worsened significantly although moderately by the end of the study (table 2). No significant change in the MADRS score was observed during follow up.

\section{Adverse events}

No permanent adverse events, in particular intracerebral haemorrhage, were observed during or immediately after surgery. A few transient adverse events were observed during the peri-operative period: three patients experienced a hypomanic state, six were confused, one had emotional lability for a few days, and two had unexpected urinary retention necessitating transurethral resection of the prostate (table 3 ). Poorly placed leads were successfully replaced in two patients because of an initially unsatisfactory clinical result. The right lead was reimplanted in one patient due to accidental disconnection. Infection of the left stimulator led to unilateral explantation before the 60 month assessment in one patient.

Stimulators (Soletra, Medtronic) were replaced in 13 patients during the 60 month postoperative period because or in anticipation of exhaustion of the battery. Transient stimulation induced side effects included muscle contractions, hypomania, and disinhibition or emotional lability. Persisting adverse effects most likely related to continuous STN stimulation included eyelid opening apraxia $(n=11)$, weight gain $(n=12)$, and hypomania $(n=2)$.

Adverse effects linked to medical treatment, STN stimulation, or progression of the disease were either transient (depression, suicide attempts, disabling dyskinesias, hallucinations, psychosis, apathy, and aggressive behaviour) or 
Table 2 Neuropsychological assessment before and 6, 24, and 60 months after neurosurgery

\begin{tabular}{lllll}
\hline & & \multicolumn{2}{l}{ After surgery } & \\
\cline { 3 - 5 } & Before surgery & 6 months & 24 months & 60 months \\
\hline UPDRS I & $2.3(2.0)$ & $2.0(1.9)$ & $2.0(2.5)$ & $3.3(2.2)^{*}+\ddagger$ \\
Mattis Scale & $140.2(3.9)$ & $138.2(9.5)$ & $132.5(15.7)$ & $134.4(8.7)^{*} \dagger$ \\
Frontal score & $43.2(7.2)$ & $40.9(8.2)$ & $39.5(11.5)$ & $36.3(10.8)^{*}$ \\
MADRS & $10.9(5.6)$ & $8.5(8.3)$ & $10.7(10.3)$ & $12.3(11.2)$ \\
\hline
\end{tabular}

Values are mean (SD).

${ }^{*} \mathrm{p}<0.013$ compared with before surgery; $\mathrm{t} p<0.013$ compared with the corresponding assessment 6 months after surgery; $\neq p<0.013$ compared with the corresponding assessment 24 months after surgery.

permanent (disinhibition or emotional lability, $\mathrm{n}=8$; addiction to levodopa treatment, $\mathrm{n}=3$; depression, $\mathrm{n}=8$; worsening of dysarthria, $\mathrm{n}=13$; disabling dyskinesias, $\mathrm{n}=8$; progressive cognitive deterioration, $\mathrm{n}=8$; and apathy, $\mathrm{n}=4$ ).

\section{DISCUSSION}

Despite the absence of a control group, our results indicate that long term post operative improvement in parkinsonian motor disability was sustained for 5 years after neurosurgery in patients with levodopa responsive PD treated by bilateral high frequency stimulation of the STN. Despite the marked improvement in motor function following STN stimulation, scores for ADL (UPDRS II "on" medication "on" stimulation), which improved transiently after the operation, declined to preoperative values 24 months after surgery. There are several possible explanations for this observation.

(i) Parkinsonian motor disability "on" medication "on" stimulation improved for only 24 months and had returned to baseline (the "on" medication condition before surgery) by the end of the follow up. Although the total and axial scores (UPDRS III) remained markedly improved following stimulation, they worsened slightly but significantly during the postoperative follow up. This was more pronounced for dysarthria, postural instability, and gait disorders (axial motor score), symptoms known to have great impact on the

Table 3 Adverse effects associated with bilateral STN stimulation (deceased patients included)

\begin{tabular}{|c|c|c|}
\hline \multirow[b]{2}{*}{ Type of adverse event } & \multicolumn{2}{|c|}{ Number of patients } \\
\hline & Transient & Permanent \\
\hline \multicolumn{3}{|l|}{ Related to neurosurgery and device } \\
\hline Urinary retention & 2 & 0 \\
\hline Delirium & 6 & 0 \\
\hline Hypomania & 3 & 0 \\
\hline Repositioning of the electrode & 3 & 0 \\
\hline Infection of the stimulator & 1 & 0 \\
\hline \multicolumn{3}{|l|}{ Related to STN stimulation } \\
\hline Eyelid opening apraxia & 0 & 11 \\
\hline Weight gain & 0 & 12 \\
\hline Muscle contractions & 4 & 0 \\
\hline Hypomania & 1 & 2 \\
\hline \multicolumn{3}{|l|}{$\begin{array}{l}\text { Related to medical treatment, } \\
\text { STN stimulation, or } \\
\text { progression of the disease }\end{array}$} \\
\hline $\begin{array}{l}\text { Disinhibition, loss of emotional } \\
\text { control }\end{array}$ & 5 & 8 \\
\hline Addiction to levodopa treatment & 0 & 3 \\
\hline Depression & 8 & 8 \\
\hline Suicide attempt & 4 & 0 \\
\hline Worsening of dysarthria & 0 & 13 \\
\hline Disabling dyskinesias & 3 & 8 \\
\hline Hallucinations & 6 & 0 \\
\hline Psychosis & 4 & 0 \\
\hline Cognitive decline & 0 & 8 \\
\hline Apathy & 4 & 4 \\
\hline Aggressive behaviour & 3 & 0 \\
\hline
\end{tabular}

quality of life of patients. ${ }^{22}$ This is consistent with the fact that axial symptoms, which respond less well to levodopa treatment, ${ }^{23}$ result from the progressive development of nondopaminergic lesions. ${ }^{24}$

(ii) Depression did not worsen during the postoperative follow up, but cognition did (table 2). We assume that significant cognitive decline, observed essentially in eight patients (table 3), had a negative effect on the activity of daily living score of the whole group of patients.

(iii) A change in the antiparkinsonian drug regimen might also be a contributing factor. This is unlikely, however, as both the marked reduction in the daily doses of levodopa and the stimulation parameters remained unchanged over the 5 year follow up (table 1). Although the doses of the antiparkinsonian treatment did not increase, motor complications became moderately but significantly more severe during the postoperative period. It may be hypothesised that the worsening of dyskinesias in many patients (table 3) was due, at least partly, to continued degeneration of the nigrostriatal dopaminergic neurons.

(iv) The numerous adverse effects observed during follow up could also have had an impact on the quality of life of the patients (table 3). Unlike the transient adverse reactions, which were successfully treated during the weeks and months following neurosurgery, several permanent complications of surgery could have interfered with the patients' ADL. Severe adverse effects, in particular cerebral haemorrhage, were not observed, but eyelid opening apraxia ${ }^{9}$ and weight gain, ${ }^{25}$ as well as hypomania and disinhibition, ${ }^{26} 27$ were frequent. They can reasonably be attributed to the stimulation procedure, though effects of antiparkinsonian medication or the progression of PD cannot be excluded. The development of dysarthria was another permanent adverse event that could have altered the quality of life of patients. The persistence of apathy and depression in several patients ${ }^{27}$ (table 3) and their probable negative effects on the personal, familial, and socio-professional status of the patients, is difficult to interpret. We presume that these symptoms resulted from factors that could not be ameliorated by neurosurgery, such as the decrease in dopaminergic transmission in extra-striatal (in particular limbic) areas that was no longer compensated for by sufficient levodopa once the daily dose was decreased (table 1), and the presence of serotoninergic and noradrenergic lesions that are characteristic of PD. ${ }^{24}$

Unexpectedly, motor disability did not worsen over 5 years (table 1). (i) Selection bias cannot be excluded in the absence of a control group. This is unlikely, however, in this homogeneous group of levodopa responsive patients with a long course of the disease. (ii) A residual effect of STN stimulation may be hypothesised ${ }^{28}$ as the delay between the interruption of stimulation and the assessment of motor disability could not be strictly the same in all patients. (iii) A neuroprotective effect of STN stimulation has been suggested in rats, ${ }^{29}$ but this remains to be demonstrated in patients. ${ }^{30}$ All these explanations are not mutually exclusive. 
In conclusion, our findings confirm the results of the previous long term study of 49 consecutive patients treated with bilateral stimulation of the STN. ${ }^{9}$ The results differ, however, from some studies performed after shorter evolution times in which far less improvement of parkinsonian motor disability was found after STN stimulation, ${ }^{6-8}$ although they are consistent with others. ${ }^{3-5}$ Differences in the clinical evaluations, neurosurgical procedures, and methods of assessment may explain inconsistencies between studies. However, we think that the marked efficacy of STN stimulation in reducing parkinsonian motor disability in our study resulted primarily from the strict selection of patients at inclusion before neurosurgery, ${ }^{31}$ and from the careful management of the patients by the same multidisciplinary team before, during, and after surgery.

\section{ACKNOWLEDGEMENTS}

The authors wish to thank Drs I Arnulf, P Bejjani, P Damier, B Pillon, J Quispe Palpa, F Torny, M Vidailhet, Y Worbe, S Yaici, and the nurses of the Centre d'Investigation Clinique for their invaluable contribution to patient care. We thank M Ruberg for editorial assistance.

\section{Authors' affiliations \\ W M M Schüpbach, N Chastan, M L Welter, J L Hoveto, V Mesnage,} A M Bonnet, V Czernecki, D Maltête, A Hartmann, L Mallet, Y Agid, Centre d'Investigation Clinique, Fédération de Neurologie, Groupe Hospitalier Pitié-Salpêtrière, Paris, France

B Pidoux, Service des Explorations Fonctionnelles Neurologiques, Groupe Hospitalier Pitié-Salpêtrière, Paris, France

D Dormont, Service de Neuroradiologie, Groupe Hospitalier PitiéSalpêtrière, Paris, France

S Navarro, P Cornu, Service de Neurochirurgie, Groupe Hospitalier Pitié-Salpêtrière, Paris, France

A Mallet, Department of Biostatistics and Medical Information, PitiéSalpêtrière Medical University, Paris, France

The study was supported by INSERM and the National Parkinson Foundation-Miami. Dr Schüpbach was supported by grants from the Swiss National Science Foundation and the Swiss Parkinson's Disease Association

Competing interests: none declared

\section{REFERENCES}

1 Schrag A, Quinn N. Dyskinesias and motor fluctuations in Parkinson's disease. A community-based study. Brain 2000;123:2297-305.

2 Limousin P, Pollak P, Benazzouz A, et al. Effect of parkinsonian signs and symptoms of bilateral subthalamic nucleus stimulation. Lancet 1995:345:91-5.

3 Limousin P, Krack P, Pollak P, et al. Electrical stimulation of the subthalamic nucleus in advanced Parkinson's disease. N Engl J Med 1998;339:1105-11

4 Rodriguez-Oroz MC, Gorospe A, Guridi J, et al. Bilateral deep brain stimulation of the subthalamic nucleus in Parkinson's disease. Neurology 2000;55(suppl 6):45-51.

5 Houeto JL, Damier P, Bejiani PB, et al. Subthalamic stimulation in Parkinson disease: a multidisciplinary approach. Arch Neurol 2000;57:461-5.
6 Broggi G, Franzini A, Ferroli P, et al. Effect of bilateral subthalamic electrical stimulation in Parkinson's disease. Surg Neurol 2001;56:89-94.

7 Kleiner-Fisman G, Fisman DN, Sime E, et al. Long-term follow up of bilateral deep brain stimulation of the subthalamic nucleus in patients with advanced Parkinson disease. J Neurosurg 2003;99:489-95.

8 Ford B, Winfield L, Pullman SL, et al. Subthalamic nucleus stimulation in advanced Parkinson's disease: blinded assessments at one year follow up. J Neurol Neurosurg Psychiatry 2004;75:1255-9.

9 Krack P, Batir A, Van Blercom N, et al. Five-year follow-up of bilateral stimulation of the subthalamic nucleus in advanced Parkinson's disease. N Engl J Med 2003;349:1925-34.

10 Defer GL, Widner H, Marie RM, et al. Core assessment program for surgical interventional therapies in Parkinson's disease (CAPSIT-PD). Mov Disord 1999; 14:572-84.

11 Hoehn MM, Yahr MD. Parkinsonism: onset, progression and mortality. Neurology 1967; 17:427-42

12 Schwab R, England A. Projection technique for evaluating surgery in Parkinson's disease. In: Gillingham FJ, Donaldson IML, eds. Third symposium on Parkinson's disease. Edinburgh, Scotland: Livingstone, 1969:152-8.

13 Deep-Brain Stimulation for Parkinson's Disease Study Group. Deep-brain stimulation of the subthalamic nucleus or the pars interna of the globus pallidus in Parkinson's disease. N Engl J Med 2001;345:956-63.

14 Schmidt R, Freidl W, Fazekas F, et al. The Mattis Dementia Rating Scale: normative data from 1,001 healthy volunteers. Neurology 1994:44:964-6.

15 Pillon B, Dubois B, Lhermitte F, et al. Heterogeneity of cognitive impairment in progressive supranuclear palsy, Parkinson's disease, and Alzheimer's disease. Neurology 1986;36:1179-85.

16 Montgomery SA, Asberg M. A new depression scale designed to be sensitive to change. Br J Psychiatry 1979;134:382-9.

17 Bejiani BP, Dormont D, Pidoux B, et al. Bilateral subthalamic stimulation for Parkinson's disease by using three-dimensional stereotactic magnetic resonance imaging and electrophysiological guidance. J Neurosurg 2000;92:615-25.

18 Rickham PP. Human experimentation. Code of ethics of the World Medical Association. Declaration of Helsinki. Br Med J 1964;5402:177.

19 Houeto JL, Welter ML, Bejiani PB, et al. Subthalamic stimulation in Parkinson disease: intraoperative predictive factors. Arch Neurol 2003;60:690-4.

20 Fahn S, Elton RL, UPDRS Development Committee. Unified Parkinson's Disease Rating Scale. In: Fahn S, Marsden CD, Calne D, et al. Recent development in Parkinson's disease. Vol 2. Florham Park, NJ: MacMillan Healthcare Information, 1987:153-63.

21 Langston JW, Widner H, Goetz CG, et al. Core assessment program for intracerebral transplantations (CAPIT). Mov Disord 1992;7:2-13.

22 Schrag A, Jahanshahi M, Quinn N. What contributes to quality of life in patients with Parkinson's disease? J Neurol Neurosurg Psychiatry 2000;69:308-12.

23 Bonnet AM, Loria Y, Saint-Hilaire MH, et al. Does long-term aggravation of Parkinson's disease result from nondopaminergic lesions? Neurology 1987;37:1539-42

24 Agid Y. Parkinson's disease: pathophysiology. Lancet 1991;1(337):1321-4

25 Barichella M, Marczewska AM, Mariani C, et al. Body weight gain rate in patients with Parkinson's disease and deep brain stimulation. Mov Disord 2003; 18:1337-40

26 Houeto JL, Mesnage V, Mallet L, et al. Behavioural disorders, Parkinson's disease and subthalamic stimulation. I Neurol Neurosurg Psychiatry 2002;72:701-7.

27 Funkiewiez A, Ardouin C, Caputo E, et al. Long term effects of bilateral subthalamic nucleus stimulation on cognitive function, mood, and behaviour in Parkinson's disease. J Neurol Neurosurg Psychiatry 2004;75:834-9.

28 Temperli P, Ghika J, Villemure JG, et al. How do parkinsonian signs return after discontinuation of subthalamic DBS? Neurology 2003:60:78-81.

29 Maesawa S, Kaneoke Y, Kajita Y, et al. Long-term stimulation of the subthalamic nucleus in hemiparkinsonian rats: neuroprotection of dopaminergic neurons. J Neurosurg 2004;100:679-87.

30 Breit S, Schulz JB, Benabid AL. Deep brain stimulation. Cell Tissue Res 2004;318:275-88.

31 Welter ML, Houeto JL, Tezenas du Montcel S, et al. Clinical predictive factors of subthalamic stimulation in Parkinson's disease. Brain 2002;125:575-83. 